\title{
Correction to: The Potato of the Future: Opportunities and Challenges in Sustainable Agri-Food Systems
}

\section{André Devaux ${ }^{1}(1)$. Jean-Pierre Goffart ${ }^{2}(1) \cdot$ Peter Kromann $^{3}(1)$.

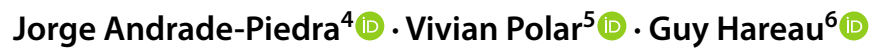

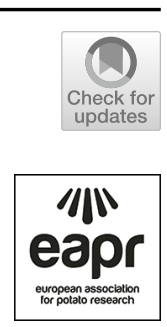

Published online: 21 August 2021

(๑) European Association for Potato Research 2021

\section{Correction to: Potato Research}

\section{https://doi.org/10.1007/s11540-021-09501-4}

The original version of the article unfortunately contained an error.

In line 4 of the abstract, it appears that by mistake a few words were added in the middle of another sentence - "especially the case in Africa where".

The correct sentence is: Food security has four dimensions: food availability, food access, food use and quality, and food stability.

Publisher's Note Springer Nature remains neutral with regard to jurisdictional claims in published maps and institutional affiliations.

The original article can be found online at https://doi.org/10.1007/s11540-021-09501-4.

André Devaux

andrej.devaux@gmail.com

1 Scientist Emeritus, International Potato Center (CIP), Ottignies-Louvain-la-Neuve, Belgium

2 Walloon Agriculture Research Center, CRA-W, Gembloux, Belgium

3 Field Crops, Wageningen Plant Research, Wageningen University \& Research, Lelystad, The Netherlands

4 Scientist, International Potato Center (CIP), Lima, Peru

5 Gender and Innovation Senior Specialist, CGIAR Research Program on Roots, Tubers and Bananas (RTB), CIP, Lima, Peru

6 Scientist, International Potato Center (CIP), Lima, Peru 